\title{
Recurrence of Focal Segmental Glomerulosclerosis (FSGS) in the Renal Allograft; an Update
}

\author{
Ahmed Aref ${ }^{1,2}$, Ajay Sharma ${ }^{2,3}$ and Ahmed Halawa ${ }^{2,4 *}$ \\ ${ }^{1}$ Department of Nephrology, Sur hospital, Oman \\ ${ }^{2}$ Faculty of Health and Science, Institute of Learning and Teaching, University of Liverpool, UK \\ ${ }^{3}$ Royal Liverpool University Hospital, UK \\ ${ }^{4}$ Sheffield Teaching Hospitals, UK
}

Submission: February 11, 2017; Published: April 12, 2017

*Corresponding author: Ahmed Halawa, Department of Nephrology, University of Sheffield-University of Liverpool, United Kingdom, Tel: 00447787542128; Email: ahmed.halawa@sth.nhs.uk

Abstract

Patients with primary focal segmental glomerulosclerosis (FSGS) have a high risk of disease recurrence post renal transplantation; this is usually characterised by significant proteinuria and associated with poor graft survival. FSGS recurrence is a challenging medical condition, not only because there is no recognised predictor of FSGS recurrence in the allograft, but also because there are no available international guidelines for treatment of this condition which add more mystery to the dilemma created by this vague syndrome.

Our work aimed to draw the attention to the latest available evidence addressing recurrence of FSGS in the renal allograft, in an attempt to improve our understanding of this condition. This also helps to guide the future studies towards the promising approaches in diagnosis and management of this condition. Ultimately this will result in better graft survival and lower the demands for another renal transplant giving the universal shortage of transplantable organs.

Keywords: Transplantation; FSGS; Recurrence; Columbia classification

Abbreviations: FSGS: Focal Segmental Glomerulosclerosisl; NSAIDs: Non-Steroidal Anti-Inflammatory Drugs; ACEI: Angiotensin-Converting Enzyme Inhibitor; ARB: Angiotensin II Receptor Blocker; SuPAR: Soluble Urokinase Receptor

\section{Discussion}

FSGS is a histological description of the glomerular pathological findings; Clinically it is characterised by proteinuria, usually of nephrotic range, hypoalbuminaemia and variable degrees of renal impairment [1]. Sever nephrotic syndrome may increase the risk of thromboembolism [2]. FSGS is classified according to the aetiology into primary (idiopathic) and secondary. Secondary FSGS may be due to infection (like HIV and parvovirus B19), drugs and toxins (pamidronate toxicity and heroin), obesity, renal atheroembolic disease and reduced functioning renal mass with hyper filtration of the remaining nephrons [1].

Another important point to be considered is the possibility of podocin gene mutation. The mutation of NPHS2 (encoding for podocin) is one of the commonest causes of the familial nephrotic syndrome. Moreover, there is convincing evidence that it occur in some patients with sporadic nephrotic syndrome [3].

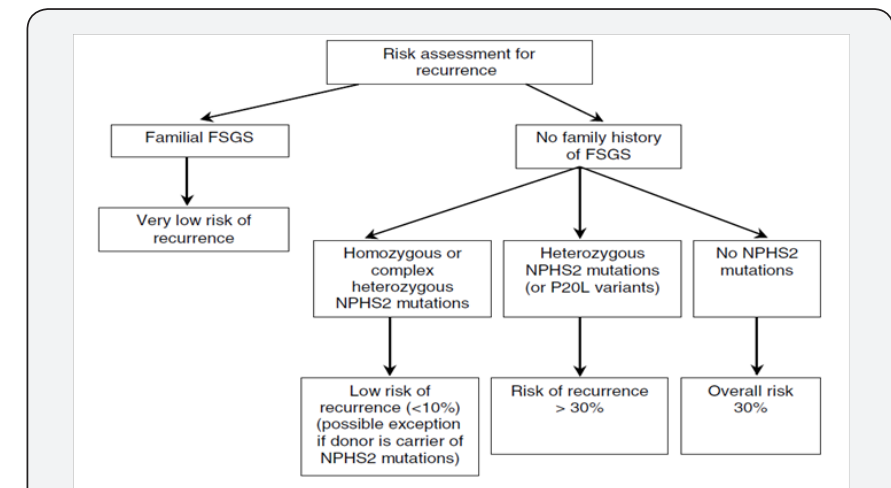

Figure 1: The risk of recurrence of FSGS [3].

The possibility of recurrent FSGS post renal transplantation is about 30\% [1,4]. Vincenti et al. [3] have simplified the risk of recurrence in the following algorithm (Figure 1) [3]. Risk factors for recurrence include childhood onset of the original disease, 
an aggressive course of rapid progression to ESRD (less than three years), collapsing variant of FSGS, podocin gene mutation and recurrence of FSGS in a previous allograft [1,3]. A paediatric study has addressed initial steroid sensitivity of the primary FSGS as a predictor of recurrence post transplantation (92.9\%), in comparison to $30.2 \%$ recurrence rate in steroid-resistant cases $(\mathrm{P}<0.001)[5]$.

It is advisable that patients with FSGS have minimal proteinuria at the time of transplantation, this will help in early detection of significant proteinuria post transplantation [3]. Thus, patients with significant proteinuria should have a trial of non-steroidal anti-inflammatory drugs (NSAIDs), with or without an angiotensin-converting enzyme inhibitor (ACEI) or angiotensin II receptor blocker (ARB) as illustrated in Figure 2. These drugs may induce what is called medical nephrectomy associated with the shutdown of the remaining kidney nephrons. Moreover, in case this strategy failed, and significant proteinuria persists, nephrectomy may be considered [3].

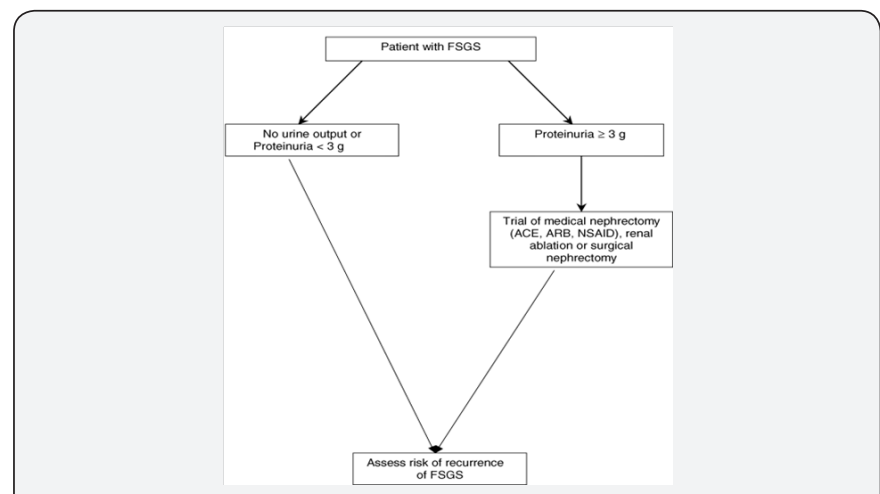

Figure 2: Pre-transplant workup and management of patients with FSGS [3].

Early diagnosis of FSGS recurrence will allow early initiation of therapy, which may reverse proteinuria and preserve kidney function $[4,6]$. However, Recurrent FSGS will result in allograft loss in more than $50 \%$ of cases $[4,7]$.

Table 1: FSGS variants identified by Columbia classification $[10,11]$.

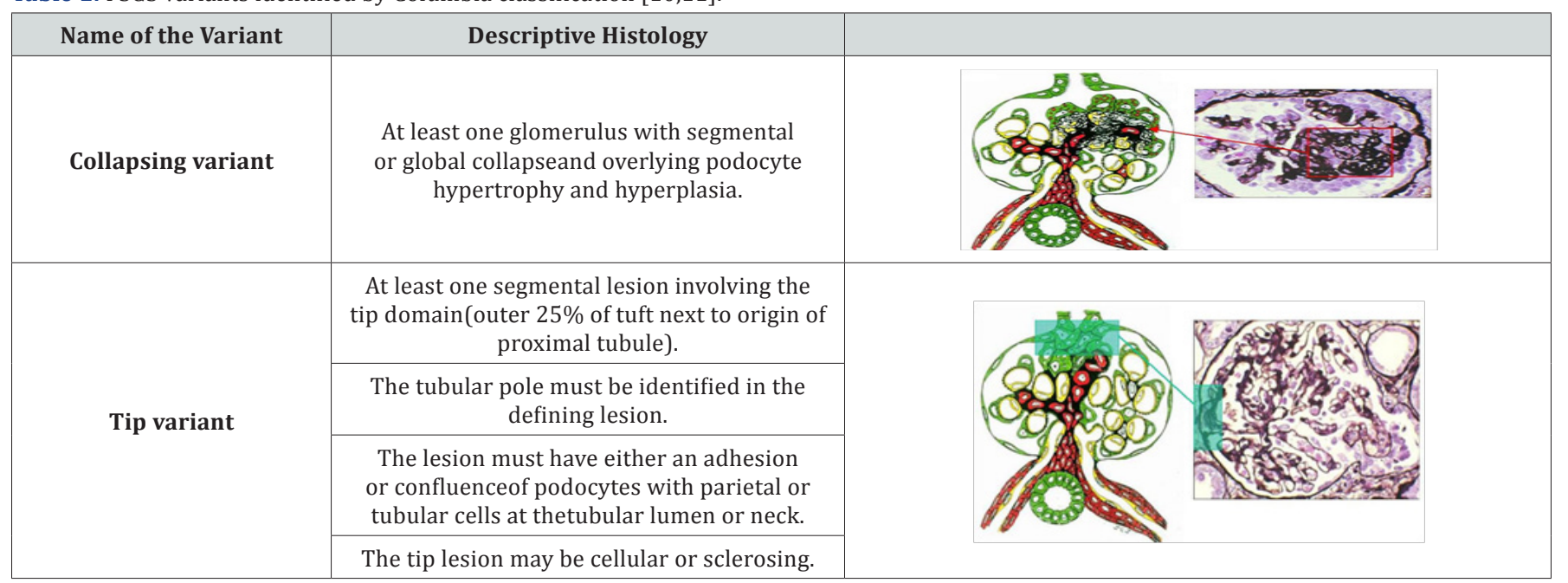

Vincenti et al. [3], suggested a protocol for screening and early detection of recurrence of FSGS. They advised to perform daily protein/creatinine ratio (P/C ratio) in spot urine sample starting from first day post transplantation and throughout the hospital stay, then weekly for one month and monthly after that till the end of the first year [3]. If the ratio is $\geq 0.5$, they advised collecting 24 hours urine sample for quantification of proteinuria. If proteinuria is more than $2 \mathrm{~g} / 24 \mathrm{~h}$, then a renal biopsy is indicated [3].

Prediction of FSGS recurrence is of great importance, as it will help in the early implementation of the therapeutic intervention. The prompt and timely initiation of therapy will result in improved patient and graft survival, reduce the cost of late intervention (including hospitalisation and the need for dialysis) and maximise the use of the available transplant organs [8]. Delville et al. [8], had identified a panel of seven antibodies (CD40, PTPRO, CGB5, FAS, P2RY11, SNRPB2, and APOL2). These antibodies if present in the serum of the recipient pretransplant, it can predict post-transplant FSGS recurrence with 92\% accuracy [8].

The pretransplant high titre of anti-CD40 antibody alone is significantly correlated with post-transplantation FSGS recurrence with about $78 \%$ accuracy [8]. Furthermore, the injection of purified human anti-CD40 antibodies, isolated from the serum of recipients with recurrent FSGS into experimental mice has led to the development of proteinuria. The proteinuria induced by these antibodies was considerably potentiated when injected with the soluble urokinase receptor (suPAR). On the other hand, injection of a CD40-blocking antibody was documented to significantly reduce the proteinuria induced by anti-CD40 antibodies in the affected mice (ACR 380.2 \pm 94.3 before versus $67.8 \pm 2.8$ after blocking; $\mathrm{P}=0.028$ ) [8].The investigators concluded that further evaluation of this antibody panel might provide a tool for pre-emptive therapeutic intervention via plasmapheresis, immunoadsorption, B lymphocyte suppression or disruption of the CD40axis by a CD40-blocking antibody [8]. 


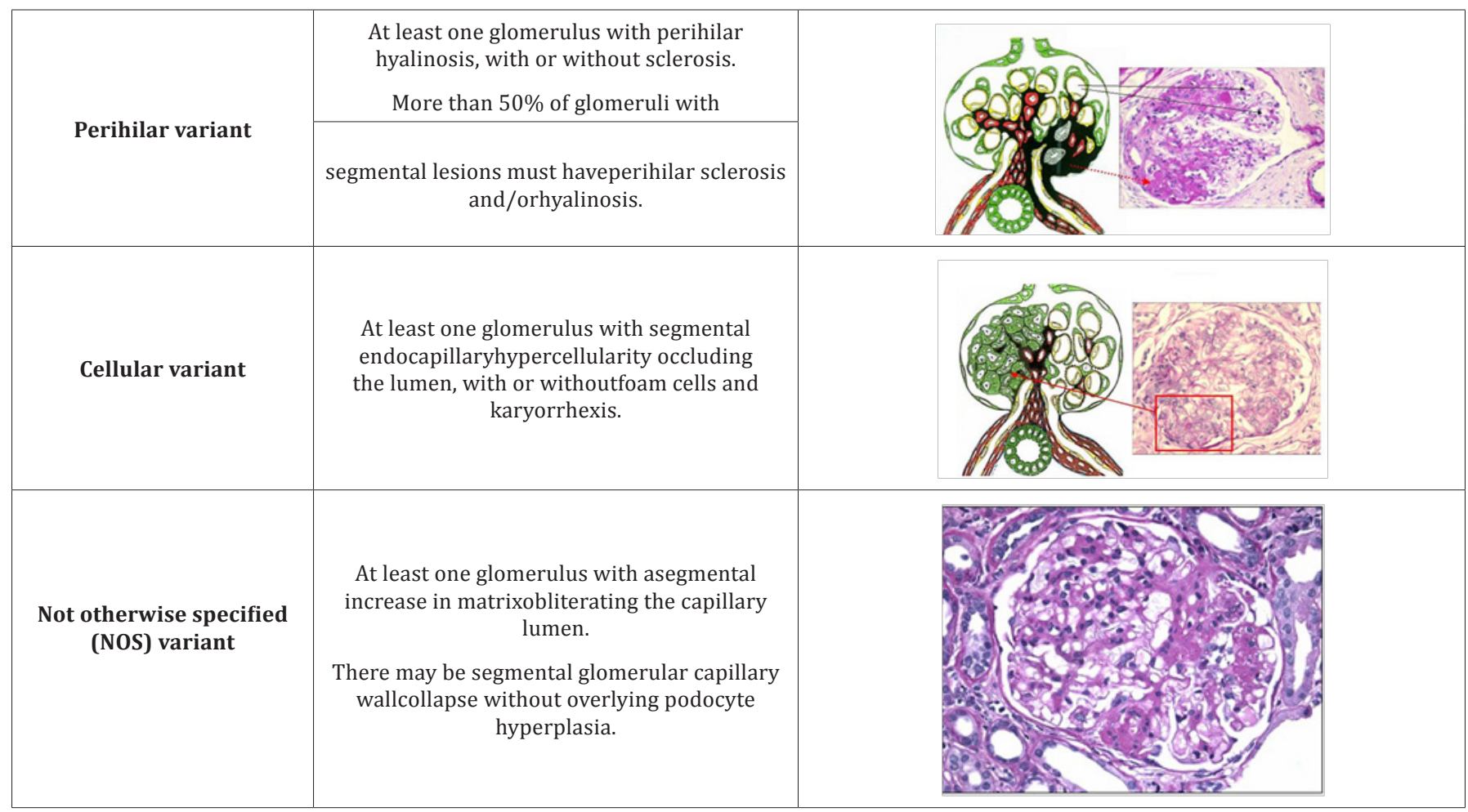

Other investigators tried to correlate the risk of recurrence with the initial histopathological findings in the native kidney biopsy [9]. The Columbia classification was introduced in 2004, and it classifies FSGS into five distinct variants based on their histological appearance in renal biopsy as illustrated in Table 1 [10].

Despite the good correlation between the Columbia classification and the clinical course of FSGS in the native kidneys, it was of no help in the prediction of recurrence post transplantation. Moreover, the histopathological findings in a case of recurrence were different from those of the native kidney, and this difference exists in the first, second and even in the third allograft [9].

The treatment of FSGS recurrence is uncertain with no available international guidelines; few studies reported beneficial results of plasmapheresis (ranging from 10-23 sessions), with or without rituximab [12]. Moreover, some centres combined plasmapheresis with cyclophosphamide (while the anti-metabolite immune suppression transiently discontinued) $[13,14]$. Both strategies showed promising results with complete or partial remission of FSGS. A reasonable approach is to start with ACEIs or ARBs in the case of persistence of significant proteinuria, then proceed to one of the abovelisted approaches depending on the patient medical condition, the potential side effects of each intervention and on the local resources.

\section{Conclusion}

The clinical course of primary FSGS can predict the recurrence in the renal allograft, while the variant of the primary disease may not have the same predictive ability. Identification of new antibodies which may be contributing to the disease recurrence and subsquinty directing the treatment is a promising approach in the management of this graft-threatening condition.

\section{References}

1. Shimizu A, Higo S, Fujita E, Mii A, Kaneko T (2011) Focal segmental glomerulosclerosis after renal transplantation. Clin Transplant 25(Suppl 23): 6-14.

2. Kayali F, Najjar R, Aswad F, Matta F, Stein PD (2008) Venous thromboembolism in patients hospitalized with nephrotic syndrome. Am J Med 121(3): 226-230.

3. Vincenti F, Ghiggeri GM (2005) New insights into the pathogenesis and the therapy of recurrent focal glomerulosclerosis. Am J Transplant. 5(6): 1179-1185.

4. Artero M1, Biava C, Amend W, Tomlanovich S, Vincenti F (1992) Recurrent focal glomerulosclerosis: natural history and response to therapy. Am J Med 92(4): 375-383.

5. Ding WY, Koziell A, McCarthy HJ, Bierzynska A, Bhagavatula MK, et al. (2014) Initial steroid sensitivity in children with steroid-resistant nephrotic syndrome predicts post-transplant recurrence. J Am Soc Nephrol 25(6): 1342-1348.

6. Hickson LJ, Gera M, Amer H, Iqbal CW, Moore TB, et al. (2009) Kidney transplantation for primary focal segmental glomerulosclerosis: outcomes and response to therapy for recurrence. Transplantation 87(8): 1232-1239.

7. Hariharan S, Adams MB, Brennan DC, Davis CL, First MR, et al. (1999) Recurrent and de novo glomerular disease after renal transplantation: a report from Renal Allograft Disease Registry (RADR). Transplantation 68(5): 635-641.

8. Delville M, Sigdel TK, Wei C, Li J, Hsieh SC, et al. (2014) A circulating antibody panel for pretransplantprediction of FSGS recurrence after kidney transplantation. Science translational medicine 6(256): 256 ra136. 
9. Canaud G, Dion D, Zuber J, Gubler MC, Sberro R, et al. (2010) Recurrence of nephrotic syndrome after transplantation in a mixed population of children and adults: course of glomerular lesions and value of the Columbia classification of histological variants of focal and segmental glomerulosclerosis (FSGS). Nephrol Dial Transplant 25(4): 1321-1328.

10. D'Agati VD, Fogo AB, Bruijn JA, Jennette JC (2004) Pathologic classification of focal segmental glomerulosclerosis: a working proposal. Am J Kidney Dis 43(2): 368-382.

11. UNC Kidney Center. Focal Segmental Glomerulosclerosis (FSGS). UNC Kidney Centre, USA.

12. Alachkar N, Wei C, Arend LJ, Jackson AM, Racusen LC, et al. (2013)
Podocyte effacement closely links to suPAR levels at time of posttransplantation focal segmental glomerulosclerosis occurrence and improves with therapy. Transplantation 96(7): 649-656.

13. Cheong HI, Han HW, Park HW, Ha IS, Han KS, et al. (2000) Early recurrent nephrotic syndrome after renal transplantation in children with focal segmental glomerulosclerosis. Nephrol Dial Transplant. 15(1): 78-81.

14. Dall'Amico R, Ghiggeri G, Carraro M, Artero M, Ghio L, et al. (1999) Prediction and treatment of recurrent focal segmental glomerulosclerosis after renal transplantation in children. Am J Kidney Dis. 34(6):1048-1055.

\section{Your next submission with Juniper Publishers will reach you the below assets}

- Quality Editorial service

- Swift Peer Review

- Reprints availability

- E-prints Service

- Manuscript Podcast for convenient understanding

- Global attainment for your research

- Manuscript accessibility in different formats

( Pdf, E-pub, Full Text, Audio)

- Unceasing customer service

Track the below URL for one-step submission https://juniperpublishers.com/online-submission.php 